co-infection in individuals with coronavirus: a rapid review to support COVID-19 antimicrobial prescribing. Clin Infect Dis. 2020;71:2459-68.

9. Vincent J-L, Sakr Y, Singer M, Martin-Loeches I, Machado FR, Marshall JC, et al.; EPIC III Investigators. Prevalence and outcomes of infection among patients in intensive care units in 2017. JAMA. 2020;323:1478-87. https:/ / doi.org/10.1001/ jama.2020.2717

10. Prestel C, Anderson E, Forsberg K, Lyman M, de Perio MA, Kuhar D, et al. Candida auris outbreak in a COVID-19 specialty care unit-Florida, July-August 2020. MMWR Morb Mortal Wkly Rep. 2021;70:56-7. https:/ / doi.org/ 10.15585/mmwr.mm7002e3

Address for correspondence: Surbhi Leekha, University of Maryland School of Medicine, 10 South Pine St, MSTF 334F, Baltimore, MD 21201, USA; email: sleekha@som.umaryland.edu

\section{Cetacean Morbillivirus and Toxoplasma gondii Co-infection in Mediterranean Monk Seal Pup, Italy}

\author{
Antonio Petrella, Sandro Mazzariol, \\ Iolanda Padalino, Gabriella Di Francesco, \\ Cristina Casalone, Carla Grattarola, \\ Giovanni Di Guardo, Camilla Smoglica, \\ Cinzia Centelleghe, Claudia Gili
}

Author affiliations: Istituto Zooprofilattico Sperimentale della Puglia e della Basilicata, Foggia, Italy (A. Petrella, I. Paladino); University of Padova, Padua, Italy (S. Mazzariol, C. Centelleghe); Istituto Zooprofilattico Sperimentale dell'Abruzzo e del Molise, Teramo, Italy (G. Di Francesco); Istituto Zooprofilattico Sperimentale del Piemonte, Liguria e Valle d'Aosta, Turin, Italy (C. Casalone, C. Grattarola); University of Teramo Faculty of Veterinary Medicine, Teramo (G. Di Guardo, C. Smoglica); Stazione Zoologica Anton Dohrn, Naples, Italy (C. Gili)

DOI: https://doi.org/10.3201/eid2704.204131

A Mediterranean monk seal (Monachus monachus) pup from the southern Adriatic coast of Italy showed cetacean morbillivirus (CeMV) and disseminated Toxoplasma gondii co-infection, which probably resulted from CeMV-induced immunosuppression. These findings are of concern for the conservation of this critically endangered species.
7 he Mediterranean monk seal (Monachus mona1 chus), the most rarely occurring pinniped worldwide, ranks among the most endangered marine mammal species. A few breeding colonies remain along the shores of Greece, Turkey, and Cyprus as well as in Atlantic waters close to Cabo Blanco, Mauritania, and Madeira (1).

Monk seals are deemed to be officially extinct in many countries, including Italy. A monk seal pup was found alive along the southern Adriatic coast of Italy; it died after rehabilitation attempts. We performed a detailed necropsy on January 28, 2020, within 12 hours after death. Postmortem examination confirmed the animal was a female weaning pup; it had a poor body condition score. During necropsy, we collected samples from the animal's brain, spinal cord, lungs, liver, kidneys, lymph nodes, spleen, intestine, muscles, and tonsils for biomolecular analyses against viral and nonviral pathogens, with special emphasis on cetacean morbillivirus (CeMV) $(2,3)$ and Toxoplasma gondii (4) (Appendix, https://wwwnc.cdc.gov/EID/ article/27/4/20-4131-App1.pdf). We fixed all the tissue samples promptly in $10 \%$ neutral buffered formalin and routinely processed them for conventional histology and for morbillivirus and T. gondii immunohistochemistry. We used a commercially available monoclonal antibody against canine distemper virus (CDV) nucleoprotein (Veterinary Medical Research and Development, https://vmrd.com) and a rabbit polyclonal antibody against $T$. gondii (MyBioSource, https://www.mybiosource.com) $(5,6)$.

We found extensive multifocal brain hemorrhages, most likely caused by a severe arteritis that also involved major cardiac vessels. The brain showed a multifocal, severe, nonsuppurative meningoencephalitis, closely associated with extensive and multifocal hemorrhages. We detected a diffuse, bilateral, chronic, and moderate interstitial pneumonia associated with a marked bronchiolar epithelial hyperplasia; we observed positive immunohistochemistry labeling for morbilliviral antigen within hyperplastic epithelial cells (Figure). Round, variably sized protozoan cysts positively stained with the T. gondii antibody were visible in the lung, within myocardial inflammatory foci, and in the tunica media of the aorta and pulmonary vessels. Lymphoid tissues exhibited a widespread and severe immune cell depletion.

Through biomolecular analyses (2,3), we detected CeMV genetic fragments in brain, lung, and spleen tissues preserved in RNAlater solution (ThermoFisher, https:/ /www.thermofisher.com) and frozen lung tissue. Fragments showed a strong homology with a CeMV isolate (complete genome GenBank 


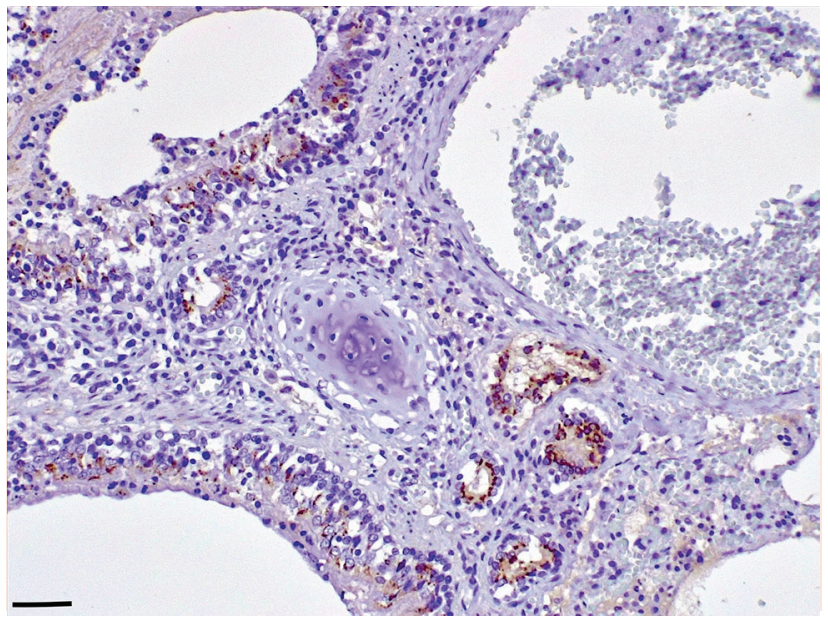

Figure. Lung tissue from a Mediterranean monk seal pup that died shortly after it was found along the southern Adriatic coast of Italy, showing positive immunostaining for morbillivirus antigen in bronchial/ bronchiolar and alveolar epithelial cells, both normal and hyperplastic. Immunohistochemical analysis using an antibody against the nucleoprotein antigen of canine distemper virus (1:100 dilution), Mayer hematoxylin counterstained. Scale bar indicates $100 \mu \mathrm{m}$.

accession no. MH430938.1): the brain fragment (GenBank accession no. MW266078) was 397 bp long and was $98.25 \%$ homologous; the lung fragment (GenBank accession no. MW266077), 402 bp long, was $98.5 \%$ homologous; and the spleen fragment (GenBank accession no. MW266079), 152 bp long, was 99.3\% homologous. In addition, we detected biomolecular positivity for T. gondii in skeletal muscle and lymph nodes, which supports immunohistochemical evidence.

Co-infections by morbilliviruses and T. gondii are well known among terrestrial and aquatic mammals, yet they have been rarely described in pinnipeds. Seals are known to be susceptible to CDV as well as to phocine distemper virus (7); CeMV infection has also been reported in monk and harbor seals (Phoca vitulina) (6). In 1997, half of the Mediterranean monk seals inhabiting the shores of Mauritania died and were found to have been infected with a CeMV-like agent; a similar virus was subsequently identified in a few monk seals from Greek waters (6). The cause of the die-off in 1997 remains unclear; biotoxins were also detected in dead seals (8).

The meningoencephalitic and pneumonic lesions found in the monk seal we investigated could also be associated with severe infection by $T$. gondii. Indeed, T. gondii-associated deaths have been reported as a significant threat to the health and conservation of Hawaiian monk seals (Neomonachus schauinslandii) (9). In the Mediterranean region, no similar cases have been previously reported other than in cetaceans, in which T. gondii has been recognized as a possible cause of death either alone or in association with CeMV (6). The young age of this monk seal suggests that CeMV or T. gondii infections could have been vertically acquired; the range of the severity and chronicity of T. gondii-associated lesions further suggest a prolonged persistence of the protozoan agent in the animal's circulation.

Previous T. gondii infection seems a plausible explanation for a subsequently acquired CeMV infection causing immunosuppression that led to disseminated toxoplasmosis. Nevertheless, we cannot exclude the possibility that CeMV acted as a primary pathogen. Previous reports of CeMV in Hawaiian monk seals, coupled with putative vertical transmission of T. gondii, indicate the need for careful evaluation of $T$. gondii and CeMV as potential threats to the health and conservation of Mediterranean monk seals. We recommend adequate and thorough seroepidemiologic and postmortem pathologic surveillance to assess the real risk posed by these 2 pathogens (10). An ad hoc infectious risk analysis protocol would enable investigators to address CeMV and T. gondii infections either separately or in combination by developing specific immunization protocols, such as those successfully employed on the Hawaiian monk seal population.

\section{Acknowledgments}

We thank the Italian National Institute for Environmental Protection and Research (ISPRA) for the support in the logistic operations before, during, and after necropsy.

\section{About the Author}

Dr. Petrella is a veterinary pathologist in the diagnostic laboratory of the Istituto Zooprofilattico Sperimentale della Puglia e Basilicata, Foggia, Italy, and serves as the regional focal point for the Italian Stranding Network. His research interests include investigations on stranded marine vertebrates.

\section{References}

1. Karamanlidis AA, Dendrinos P, Larrinoa PF, Gücü AC, Johnson WM, Kiraç CO, et al. The Mediterranean monk seal Monachus monachus: status, biology, threats, and conservation priorities. Mammal Rev. 2016;46:92-105. https://doi.org/10.1111/mam.12053</jrn>

2. Centelleghe C, Beffagna G, Zanetti R, Zappulli V, Di Guardo G, Mazzariol S. Molecular analysis of dolphin morbillivirus: a new sensitive detection method based on nested RT-PCR. J Virol Methods. 2016;235:85-91. https:// doi.org/10.1016/j.jviromet.2016.05.005

3. Beffagna G, Centelleghe C, Franzo G, Di Guardo G, Mazzariol S. Genomic and structural investigation on dolphin morbillivirus (DMV) in Mediterranean fin whales (Balaenoptera physalus). Sci Rep. 2017;7:41554. https://doi.org/10.1038/srep41554 
4. De Craeye S, Speybroeck N, Ajzenberg D, Dardé ML, Collinet F, Tavernier $\mathrm{P}$, et al. Toxoplasma gondii and Neospora caninum in wildlife: common parasites in Belgian foxes and Cervidae? Vet Parasitol. 2011;178:64-9. https://doi.org/10.1016/j.vetpar.2010.12.016

5. Cruickshank JJ, Haines DM, Palmer NC, St Aubin DJ. Cysts of a Toxoplasma-like organism in an Atlantic bottlenose dolphin. Can Vet J. 1990;31:213-5.6. Van Bressem MF, Duignan PJ, Banyard A, Barbieri M, Colegrove KM, De Guise $S$, et al. Cetacean morbillivirus: current knowledge and future directions. Viruses. 2014;6:5145-81. https:// doi.org/10.3390/v6125145

7. Duignan PJ, Van Bressem MF, Baker JD, Barbieri M, Colegrove KM, De Guise S, et al. Phocine distemper virus: current knowledge and future directions. Viruses. 2014;6:5093-134. https:// doi.org/10.3390/v6125093

8. Hernández M, Robinson I, Aguilar A, González LM, López-Jurado LF, Reyero MI, et al. Did algal toxins cause monk seal mortality? Nature. 1998;393:28-9. https://doi.org/10.1038/29906

9. Barbieri MM, Kashinsky L, Rotstein DS, Colegrove KM, Haman KH, Magargal SL, et al. Protozoal-related mortalities in endangered Hawaiian monk seals Neomonachus schauinslandi. Dis Aquat Organ. 2016;121:85-95. https:/ / doi.org/10.3354/dao03047

10. Robinson SJ, Barbieri MM, Murphy S, Baker JD, Harting AL, Craft ME et al. Model recommendations meet management reality: implementation and evaluation of a network-informed vaccination effort for endangered Hawaiian monk seals. Proc Biol Sci. 2018; 285:20171899. https:/ / doi.org/10.1098/rspb.2017.1899

Address for correspondence: Sandro Mazzariol, Department of Comparative Biomedicine and Food Science, Viale dell'Università 16, 35020, Legnaro (PD), Italy; email: sandro.mazzariol@unipd.it

\section{Increased Likelihood of Detecting Ebola Virus RNA in Semen by Using Sample Pelleting}

\author{
Courtney M. Bozman, Mosoka Fallah, \\ Michael C. Sneller, Catherine Freeman, \\ Lawrence S. Fakoli III, Bode I. Shobayo, \\ Bonnie Dighero-Kemp, Cavan S. Reilly, Jens H. Kuhn, \\ Fatorma Bolay, Elizabeth Higgs, Lisa E. Hensley \\ Author affiliations: National Institutes of Health, Frederick, \\ Maryland, USA (C.M. Bozman, B. Dighero-Kemp, J.H. Kuhn, \\ L.E. Hensley); National Public Health Institute of Liberia,
}

Monrovia, Liberia (M. Fallah, C. Freeman, L.S. Fakoli III, B.I. Shobayo, F. Bolay); National Institutes of Health, Bethesda, Maryland, USA (M.C. Sneller, E. Higgs); University of Minnesota, Minneapolis, Minnesota, USA (C.S. Reilly)

DOI: https://doi.org/10.3201/eid2704.204175

Ebola virus RNA can reside for months or years in semen of survivors of Ebola virus disease and is probably associated with increased risk for cryptic sexual transmission of the virus. A modified protocol resulted in increased detection of Ebola virus RNA in semen and improved disease surveillance.

Doir uring 2013-2016, Ebola virus (EBOV; family Filoviridae, genus Ebolavirus, species Zaire ebolavirus) caused an unprecedented outbreak of Ebola virus disease (EVD) that began in Guinea and subsequently affected Liberia, Sierra Leone, and, to a much lesser degree, several other countries in West Africa. Due in part to the lack of medical infrastructure and response preparedness in these countries, the outbreak ultimately involved 28,652 human infections and 11,325 deaths $(1,2)$.

The large number of EVD survivors enabled detailed studies, such as the Partnership for Research on Ebola Virus (PREVAIL) III study (3), which aimed at characterizing potential EVD sequelae and EBOV persistence in a cohort of 1,144 EVD survivors in Liberia over the course of 5 years. An unexpected observation of these studies was the persistence of EBOV RNA and sometimes-replicating EBOV in the brain, eyes, and semen of survivors (4). EBOV RNA persistence in semen of EVD survivors, measurable up to 40 months $(3,5)$, has been associated with rare events of sexual EBOV transmission and EVD outbreak flareups (6).

Assuming a causal relationship between EBOV RNA and EBOV presence in semen, we collaborated with the overseas response team to initiate an ongoing (and unpublished) trial, PREVAIL IV, to counter sexual EBOV transmission from survivors through reduction of viral RNA concentrations in semen by using the candidate medical countermeasure remdesivir. However, interpretation of data obtained in studies such as PREVAIL IV is crucially dependent on the sensitivity of EBOV RNA detection in semen samples.

The GeneXpert Systems (Cepheid, https://www. cepheid.com) are diagnostic platforms that implement single-use cartridges to simultaneously extract and detect RNA by using reverse transcription PCR. During PREVAIL III (3), the GeneXpert IV System was applied to standard processing of EBOV survivor semen 